Fixed Point Theory, 21(2020), No. 1, 151-166

DOI: $10.24193 /$ fpt-ro.2020.1.11

http://www.math.ubbcluj.ro/ nodeacj/sfptcj.html

\title{
MULTIVALUED ITERATED CONTRACTIONS
}

\author{
T. DOMÍNGUEZ BENAVIDES*, P. LORENZO RAMÍREZ**, M. RAHIMI*** \\ AND A. SADEGHI HAFSHEJANI**** \\ *Departamento de Análisis Matemático, Universidad de Sevilla, \\ P.O. Box 1160, 41080-Sevilla, Spain \\ E-mail: tomasd@us.es \\ ** Departamento de Análisis Matemático, Universidad de Sevilla, \\ P.O. Box 1160, 41080-Sevilla, Spain \\ E-mail: ploren@us.es \\ *** Department of Mathematics, University of Isfahan, \\ Isfahan, 81745-163, Iran \\ E-mail: marzie.rahimi@sci.ui.ac.ir \\ **** Department of Mathematics, Yazd University, \\ P. O. Box. 89195-741, Yazd, Iran \\ E-mail: sadeghia@stu.yazd.ac.ir
}

\begin{abstract}
This paper focus on the class of multivalued iterated contractions, mappings which are contractive throughout the orbits. We show that the proof of Nadler's theorem still holds for these mappings whenever they satisfy a rather weak type of continuity, which gives us a new fixed point theorem. We show several types of mappings that properly contain Suzuki $(C)$-type generalized contraction mappings and for which our fixed point results apply. We conclude the paper showing some further examples of iterated contraction mappings which are, respectively, the mappings satisfying condition $(B)$ and an extension to the multivalued case of mean iterated contractions and we also obtain fixed point results for these classes of mappings.

Key Words and Phrases: Fixed point, multivalued mappings, generalized contraction mappings, metric spaces.

2010 Mathematics Subject Classification: 47H04, 47H09, 47H10.

Acknowledgement. The first and second authors are partially supported by MINECO, Grant MTM2015-65242-C2-1-P and Andalusian Regional Government Grant FQM-127. We are indebted to M. A. Japón and the anonymous referee for their valuable suggestions to improve this manuscript. This research was done while the third and fourth authors were visiting the University of Seville. They are grateful to the Department of Mathematical Analysis for its hospitality.
\end{abstract}

\section{REFERENCES}

[1] J.P. Aubin, H. Frankowska, Set-Valued Analysis, Birkhäuser, Boston, 1990.

[2] T. Domínguez Benavides, E. Llorens-Fuster, Iterated nonexpansive mappings, J. Fixed Point Theory Appl., 20(2018), no. 3, 20-104. 
[3] D. Dorić, R. Lazović, Some Suzuki type fixed point theorems for generalized multivalued mappings and applications, Fixed Point Theory Appl., (2011), 2011:40.

[4] R. Espínola, P. Lorenzo, A. Nicolae, Fixed points, selections and common fixed points for nonexpansive-type mappings, J. Math. Anal. Appl., 382(2011), 503-515.

[5] Y. Feng, S. Liu, Fixed point theorems for multi-valued contractive mappings and multi-valued Caristi type mappings, J. Math. Anal. Appl., 317(2006), 103-112.

[6] K. Goebel, M.A. Japón Pineda, On a type of generalized nonexpansiveness, Fixed Point Theory and Its Applications, 71-82, Yokohama Publ., Yokohama, 2008.

[7] K. Goebel, B. Sims, Mean Lipschitzian mappings, Nonlinear Analysis and Optimization I. Nonlinear Analysis, 157-167, Contemp. Math., 513, Israel Math. Conf. Proc., Amer. Math. Soc., Providence, RI, 2010.

[8] T. Kamran, Mizoguchi-Takahashi's type fixed point theorem, Comp. Math. Appl., 57(2009), $507-511$.

[9] R. Kannan, Some results on fixed points, Bull. Calc. Math. Soc., 60(1968), no. 1, 71-77.

[10] E. Karapinar, K. Taş, Generalized $(C)$-conditions and related fixed point theorems, Comput. Math. Appl., 61(2011), no. 11, 3370-3380.

[11] M. Kikkawa, T. Suzuki, Three fixed point theorems for generalized contractions with constants in complete metric spaces, Nonlinear Anal., 69(2008), 2942-2949.

[12] W.A. Kirk, B. Sims (eds.), Handbook of Metric Fixed Point Theory, Dordrecht, Kluwer Academic Publishers, 2001, 391-435.

[13] L.J. Lin, C.S. Chuang, Z.T. Yu, Fixed point theorems for mappings with condition (B), Fixed Point Theory and Applications, 2011, 2011:92.

[14] E. Llorens-Fuster, E. Moreno-Gálvez, The fixed point theory for some generalized nonexpansive mappings, Abstr. Appl. Anal. (2011), Art. ID 435686.

[15] N. Mizoguchi, W. Takahashi, Fixed points theorems for multivalued mappings on complete metric space, J. Math. Anal. Appl., 141(1989), 177-188.

[16] S.B. Nadler jr., Multi-valued contraction mappings, Pacific J. Math., 30(1969), 475-488.

[17] J.M. Ortega, W.C. Rheinboldt, Iterative Solutions of Nonlinear Equations in Several Variables, Academic Press, New York, 1970, reprinted as "Classics in Applied Mathematics", Vol. 30, SIAM Publications, Philadelphia, PA.

[18] R. Pant, R. Shukla, Approximating fixed points of generalized $\alpha$-nonexpansive mappings in Banach spaces, Numer. Funct. Anal. Optim., 38(2017), no. 2, 248-266.

[19] I.A. Rus, Generalized Contractions and Applications, Cluj University Press, Cluj-Napoca, Romania, 2001.

[20] S.L. Singh, S.N. Mishra, Coincidence theorems for certain classes of hybrid contractions, Fixed Point Theory Appl., Vol. 2010, Art. ID 898109.

[21] T. Suzuki, Fixed point theorems and convergence theorems for some generalized nonexpansive mappings, J. Math. Anal. Appl., 340(2008), 1088-1095.

Received: July 13, 2018; Accepted: March 19, 2019. 
MULTIVALUED ITERATED CONTRACTIONS 